\title{
Optimization of multi-objective land use model with genetic algorithm
}

\author{
Hasan Mutlu*(D)
}

\begin{abstract}
The first task of the city planner is to effectively locate integrated land use types for various objectives. The Multi Objective Land Use Planning Model developed to achieve this goal, aims to maximize land value and minimize the transportation. The genetic algorithm method developed to find the optimum layout according to the MultiObjective Land Use Planning Model has been explained, the success and performance of the process has been tested with artificial data, and its usability in real problems has been examined. According to the results of the study, using this method, it is revealed that layout plans that are very close to the maximum efficiency value can be found within 1 day in cities with a population of up to 1,000,000, within 1 week in cities up to $5,000,000$, and within 1.5 months in cities close to $16,000,000$. By examining the results, the deficiencies of this method are determined and the suggestions for improvement of this method are stated. The problem chosen in this study is a problem that most city planners have to solve and the developed application has been opened to the use of other experts. This makes this work unique as it allows planning experts who are incapable of developing such methods to experiment.
\end{abstract}

Keywords: multi objective land use planning, spatial optimization, genetic algorithm

\section{Introduction}

A city consists of various functions that serve different objectives and affect each other differently. The spatial organization of the city includes a wide network of relationships formed by these interconnected elements. For example, shopping malls want to be close to the customer first, commercial companies want to be close to their workforce and other companies they are related to, and individuals want to be close to workplaces, schools and shopping places. The first task of the city planner is to effectively locate integrated functions for various objectives. This is an important task, and sometimes even a mistake made in the decision of insignificant land use can be an important factor in the functional and economic development of the city in a long time (Dökmeci, 2015).

Haque \& Asami (2014) stated that the urban land use decision-making process is always complex and the reasons for this complexity are the increased participation of stakeholders, the variety and variability of interests and priorities, as well as the contradictory, non-linear and non-aggregable nature of goals. They stated that land use allocation is a multi-objective optimization problem. 
In recent years, there has been an increase in models developed for the solution of land use problems. The developments in heuristic algorithm methods and the increase in computer computing power allow the development of such models and produce usable results.

This study aimed to examine how these developed methods can be beneficial for experts through a sample application. The optimum solution of the Multi-Objective Land Use Planning Model, which was described by Dökmeci (2015) as a problem was determined, the methods that can be used to solve this problem were evaluated, an application using genetic algorithm was developed, the success rate of this application was analyzed and the usage possibilities were evaluated. In order to determine the parameters of the genetic algorithm, a model was created with the multiple regression analysis method, and a statistical relationship was determined between the value of the parameters and the success rate and processing time.

While explaining land use allocation optimization techniques, special applications developed are taken as reference and these applications cannot be tried by the user. The problem chosen in this study is a problem that most city planners have to solve, and the developed application has been opened to the use of experts. This makes this study unique as it allows planning experts who are incapable of developing such methods to try it out. Rogers (2003) stated the characteristics that will be determinant in the spread of innovations as relative advantage, compatibility, complexity (simplicity), trialability achiveand observability. Simple and understandable model in this study which can be tried will help these methods to become widespread.

Dökmeci (2015) considers two objectives in this model. 1) Maximum profit 2) minimizing the distance between interrelated functions.

According to the first objective, the value of a land is considered to depend on the land use surrounding it. The city structure is shaped according to the most efficient land use resulting from the competition of urban functions for location selection.

There are movement of goods and people between each land use unit and its surrounding units in the city. The location of each unit is very tightly dependent on the location of the other units. The second objective is to minimize the transportation between various land uses.

$$
\operatorname{Max} z=\sum_{i=1}^{r} \sum_{j=1}^{r} \frac{V_{i j}}{1+d_{i j}^{\alpha}}
$$

$z=$ Total income from land use in the area.

$V_{i j}=$ Interaction of land use types $\mathrm{i}$ and $\mathrm{j}$ in terms of value

$d_{i j}=$ Distance between land use types $\mathrm{i}$ and $\mathrm{j}$

$\alpha=$ Distance influence coefficient

$r=$ Land use type count

$$
\operatorname{Min} T=\sum_{i=1}^{r} \sum_{j=1}^{r} u_{i j} d_{i j} b_{i j}
$$

$\mathrm{T}=$ total transportation

$u_{i j}=$ transport demand between land use types $\mathrm{i}$ and $\mathrm{j}$

$b_{i j}=$ if there is a transport link between land use types $\mathrm{i}$ and $\mathrm{j}, 0$ otherwise 
There is a need for a multi-objective decision making method that will evaluate the result by balancing two different objectives. This multi-objective evaluation method is given in the figure below.

$$
E(a)=\sum_{k=1}^{n} u_{k} e_{k}(a)
$$

$E(a)=$ Total efficiency of alternative $a$,

$u_{k}=$ coefficient indicating the importance of the objective $\mathrm{k}$,

$e_{k}(\mathrm{a})=$ the effectiveness of alternative a for objective $\mathrm{k}$,

$\mathrm{n}=$ number of goals

Our problem is to find the most efficient distribution of $r$ numbers of land uses to $c$ numbers of cells. According to the brute force method, this problem consists of calculating the efficiency values of $r^{c}$ layout and choosing the best one. In a region consisting of 4 land use types and 20 cells, the effectiveness of $4^{20}$, ie $1,099,511,627,776$ layout should be calculated. If we assume that we calculate each plan in 1 second, we will need 34,865 years for all.

\section{Optimization Approaches and Methods in Land Use Decisions}

Arslanlı (2016) using the Hansen Model, cost-benefit analysis and multi-objective land use location model, aimed to place the population of 3,000,000 in Istanbul in suitable districts and locations in their research. Land use location selection model was used to determine how many sub-centers in districts is more effective.

Cao et al. (2011) defined land use optimization as different activities or land uses assigned to land area units that usually takes place at the city, sometimes neighborhood or urban scale.

Eldrandaly (2010) defined land use planning as a specific allocation problem which the planner tries to achieve the determined goals by changing land use rates and locations.

Tong \& Murray (2012) stated that it is not appropriate to use exact methods in the optimization problem, because of the lack of a definitive solution method, the allocated time phase of the computation time, to focus on a single solution and not produce near-optimal alternatives. They stated that the heuristic method is an approach based on the practical rules, strategies and temporary procedures to be developed for the solution of the optimization problem and this method aims to determine the solution space in a way and find the best solution among the feasible solutions in this space.

Loonen, Heuberger, \& Kuijpers-Linde (2007) stated that the most commonly used methods for land use are mathematical programming methods (linear programming, nonlinear programming, mixed-integer programming) and pseudo-heuristic methods (genetic algorithms, evolutionary programming, simulated annealing, neural networks).

Stewart, Janssen, \& van Herwijnen (2004) stated that recent trends in land use planning cause the need to develop different types of algorithms. These trends; increasing stakeholder participation, increasing the complexity of the decision problem, using geographic information systems and using interactive decision support systems.

Liu et al. (2015) divided existing land use optimization models into three categories:

1. Linear programming models

2. Cellular automata models

3. Models based on intelligent algorithms 
Xia, Liu, Liu, He, \& Hong (2014) classified the current methods used to create land use zones on a regional scale in 4 categories:

1. Spatial superposition analysis

2. Multi-criteria analysis

3. Integer programming

4. Heuristic approaches

Linear programming models can quickly determine the most suitable land use structure based on specific land targets and constraints. However, these models cannot change the land use of the parcels and cannot make spatial optimization. Cellular automata models are based on land use conversion rules for local areas and can produce different land use patterns under different conditions using a bottom-up approach. Irrational land use in local areas can be adjusted using well designed land use conversion rules. However, optimization goals and other important macroeconomic factors cannot be easily incorporated into cellular automaton models (Liu et al., 2015).

Liu et al. (2015) created a land use spatial optimization model by combining a genetic algorithm and game theory. The genetic algorithm is continuously executed to optimize the spatial layout of each land use type separately. Using competitive zones as core units, the model draws on multistakeholder games and land use planning information to coordinate local land use competitions. The land use model of the solution is more rational than the current land use.

Li \& Parrott (2016) prepared an advanced genetic algorithm that solves a model that aims maximum benefit, maximum ecological benefit, maximum convenience and maximum compactness in Okanagan (Canada). This model also contains constraints on housing demand and various regulations. The results of the study showed that the proposed method is consistent and can create an optimal land use scenario according to the preferred goals of stakeholders, thus having the potential to provide interactive technical support for land use planning. In this study, they also stated that future studies on land use optimization should focus on parallel computing to increase productivity and how to adequately consider future macro factors during the goalconstraint definition process.

Masoomi, Mesgari, \& Hamrah (2013) used the multi objective particle swarm optimization algorithm, which is a type of genetic algorithm, for optimum land use placement at parcel level. They aimed to maximize compatibility, dependency, convenience and compactness. In this study, it was stated that the best alternatives could be determined for these 4 objectives and the most suitable among them could be determined from the Pareto Front chart. It was observed that the results produced significantly more successful results than current land use. In this study, they stated that good results can be obtained if the algorithm runs for a long time. It will be useful to investigate how the population number can be determined to increase the convergence speed of the algorithm.

Schwaab et al. (2018) examined different combinations of different crossover and mutation operators to improve the performance of genetic algorithms for multi-objective land use problems. As a result of the study, it has been shown that the use of different mutation operators, which includes at least one heuristic algorithm is more successful because it makes it possible to produce more different layouts.

\section{Developed Genetic Algorithm and Application}

According to the literature research, it was observed that using heuristic algorithm gives better results for optimum land use assignment and a special application was developed for this problem by using genetic algorithm approach. Details of this application will be explained later. The application can be reached from the following link: http://www.hasanmutlu.com/index.php/land- 
use-optimization/. The figures about the application are given at the end of the article. To use the software, first which land use types will be used should be selected. The number of rows and columns in the layout plan, the amount of transportation between these land use types and the value effect are entered (Figure 17). Later, in the land use drawing, the current situation is assigned to the cells or a random initial plan is generated (Figure 18). The efficiency value of the first assigned layout is calculated, the total value of the transportation, the total land value, the transportation importance coefficient and the land value importance coefficients are entered for the multiobjective decision and the efficiency value is calculated. In order to calculate the best layout, the layout plan and genetic algorithm parameters to be used are specified and calculations are made (Figure 19). The success of the process is evaluated by examining the resulting layout plan and the activity chart according to generations (Figure 20).

While developing the application, during the calculation of the location efficiency, the highest performance was obtained from the existing hardware by using the parallel algorithm.

Inputs:

- Basic layout map. In this map, the starting locations of land uses, prohibited areas, areas where land use will never change are indicated. Total cell count for each land use type will maintain.

- Total amount of transportation between each land use

- Value impact between each land use

- Alpha coefficient to be used for the effect of distance

- Maximum value of transportation, importance coefficient of transportation, total land value, importance coefficient of land value in order to calculate efficiency value.

- Number of populations in generation: Specifies the number of random layouts that will be created in each generation.

- Number of generations to be produced.

- Mutation Rate: It is the mutation rate to be applied while generating a new random layout plan.

\section{Algorithm:}

- Basic layout map is obtained.

- In the first generation, random layout plans are produced as much as the population number with the mutation rate determined from this map.

- Each layout plan is ranked according to its activity.

- If there are not as many generations as the number of generations produced;

- The worst generation is removed from the list, the best generation is added one more.

- Effectiveness of the layouts in the population is calculated.

- Each layout plan is ranked according to its activity.

- 1 child placement is created by applying the Partially Matched Crossover (PMX) method to 2 parents randomly selected according to the roulette wheel method as much as the population number. (Those with higher efficiency are more likely to enter the crossover process.)

- Mutation is applied to the child layouts at the determined mutation rate. The new generation is formed.

- The layout plan activity of the new population is calculated.

- Each layout plan is ranked according to its activity.

- The cycle continues.

- If the specified number of generations is reached, the process is completed, and the most efficient layout in the last generation is found as a result. 
Details of the crossover process are shown in the Figure 1. This process explained by Taşkın \& Emel (2009).
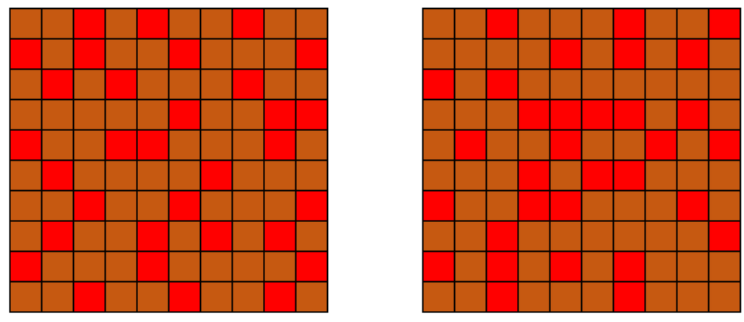

Trading (32 Cell)

Housing (64 Cell)

Page | 20

A Layout

A Layout Selected For Base

B Layout

$\sqrt{2}$

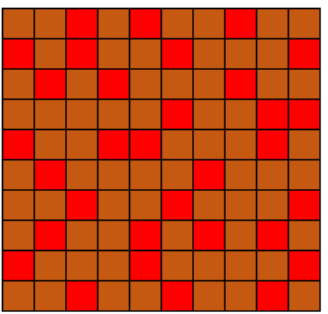

Randomly 3. Row, 4 .Column - 7. Row 7. Column Selected

$\sqrt{1}$

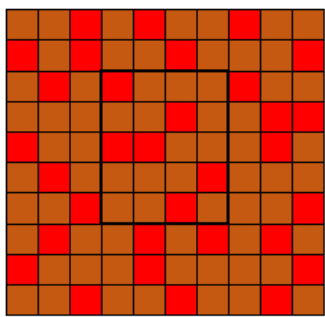

Cells Within Selected Area Come From Other Parent (B)

$\sqrt{1}$

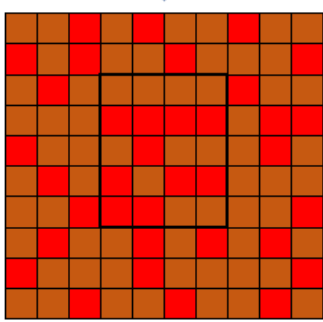

Land Use Type Count Operator Runs

Trading Increase 4

Housing Decrease 4

Randomly 4 Trading Cell Outside The Selected Area Change To Housing

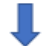

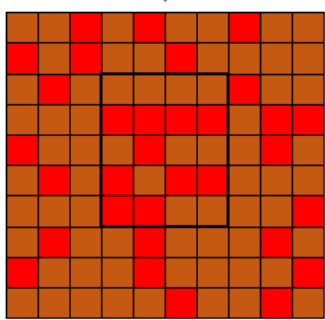

Figure 1 Details of the crossover process 
By examining whether the solution of the determined problem is possible with the genetic algorithm, it has been evaluated whether this method can be used in land planning spatial decisions.

An artificial layout area was created in 2 different size and data prepared; the efficiency values were calculated by running the application with different parameters on these data. The

Page| 21 parameters and efficiency values in the same data were examined by regression analysis and it has been tried to determine whether the real result (the most effective layout) can be achieved with this method.

\section{Model Parameters:}

Since an imaginary data is produced, transportation and value effect parameters are determined according to the general approach. According to these parameters, there is not much transportation between residentials, there is no transportation between tradings and the amount of transportation between residentials and tradings is high (Table 1 and Table 2). There is high level of transport between the residentials and industry. Recreation area is moderately accessible from residential and trading areas. Residential area has moderate positive impact on residential land value, trading has high amount of positive effect on trading and residential land value. The industry has negative value effect on residential and recreation areas, and the industry has high positive impact on other industries. Being close to residential has high effect, being close to trade has positive effect on industry. Importance of transportation is defined as 0.25 and importance of land value is defined as 0.75 . Thus, residentials with high land value will be more effective.

Table 1 Transportation values

\begin{tabular}{|c|c|c|c|c|}
\hline & Residential & Trading & Industry & Recreation \\
\hline Residential & 2 & 8 & 10 & 6 \\
\hline Trading & 8 & 0 & 5 & 0 \\
\hline Industry & 10 & 0 & 0 & 0 \\
\hline Recreation & 6 & 5 & 0 & 0 \\
\hline
\end{tabular}

Table 2 Land value impacts

\begin{tabular}{|c|c|c|c|c|}
\hline & Residential & Trading & Industry & Recreation \\
\hline Residential & 5 & 10 & -7 & 10 \\
\hline Trading & 10 & 10 & 0 & 5 \\
\hline Industry & 10 & 5 & 10 & 0 \\
\hline Recreation & 10 & 5 & -10 & 0 \\
\hline
\end{tabular}

4. Data and Analysis

All processes were run on an Intel(R) Core (TM) i7-8750H CPU @2.20 2.21 GHz Windows 10 computer.

\section{First Artificial Data}

Most efficient layout of 64 residential area and 35 trade area is calculated with these 10 rows, 10 column data.

With the parameters, the application reaches which efficiency values is seen in Figure 2.

The trend line is logarithmic and the $R^{2}$ value is set at 0.7439 . The time graph is also shown in Figure 3. Trend line is linear and $R^{2}$ value is set at 0.9998 . When the layout plans are examined 
according to their generations (Figure 4), it is observed that as the number of generations increases, the trade clusters in more centers as expected.

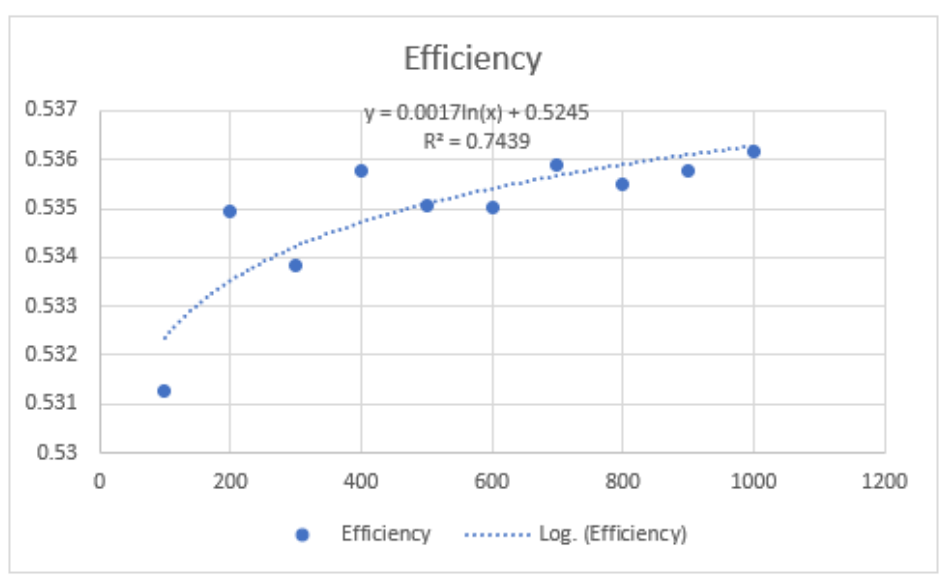

Figure 2 Efficiency chart by generation number

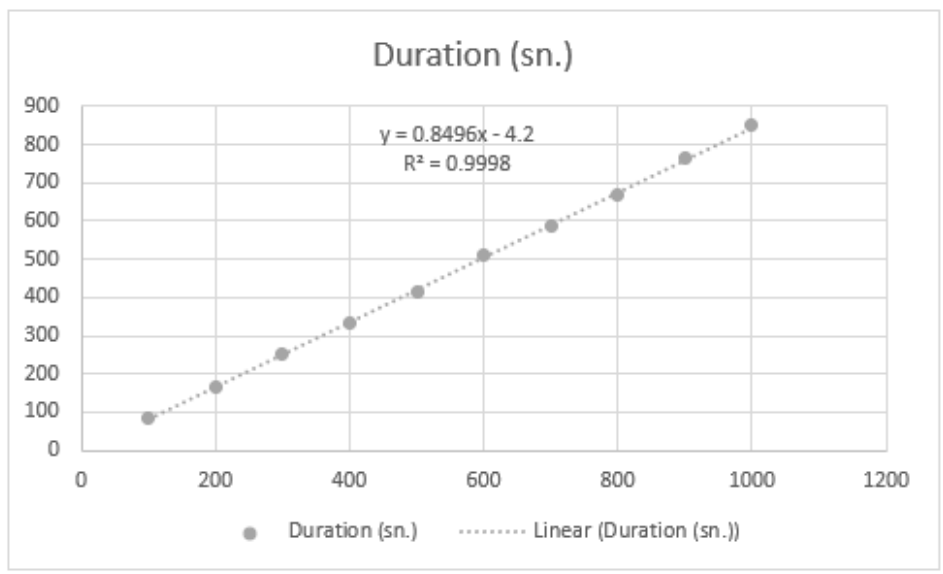

Figure 3 Time graph according to the number of generations

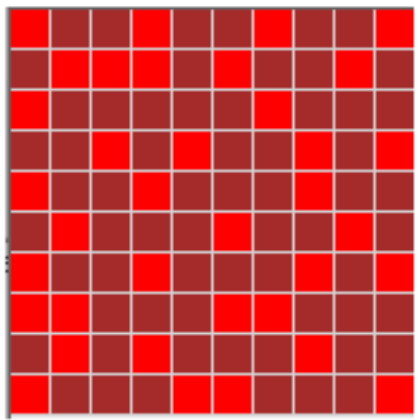

Main Layout

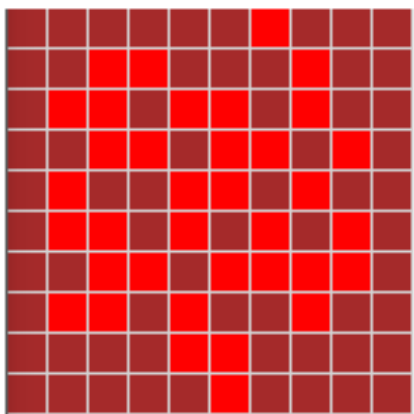

Generation 500

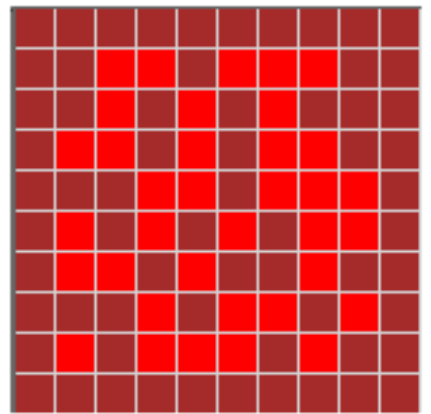

Generation 1000

Figure 4 Layouts according to generations

In a 100-cell layout, a result close to what was expected was obtained in 900 seconds. It is getting more difficult to get more efficient results according to efficiency chart (Figure 2). However, who use this method and examine the layout plans according to the increase in generation values, they can predict the best layout pattern. 


\section{Second Artificial Data:}

In this data, a 400 -cell layout consisting of 20 rows and 20 columns was created, the best layout pattern of 252 residences, 64 trade, 64 industry and 20 recreation cells was tried to locate. As a result of this analysis, the following efficiency chart is created (Figure 5 ). The trend line of this graph is logarithmic and the $R^{2}$ value is determined as 0.4699 . This value has shown us that generations with 200 populations in so many cells will not produce consistent results. For this reason, the application was run for 500 populations. As a result of this study, the $R^{2}$ value was found to be 0.823 (Figure 6 ). The trend line of the process duration was formed linearly and the $\mathrm{R}^{2}$ value was found to be 0.9998 (Figure 7).

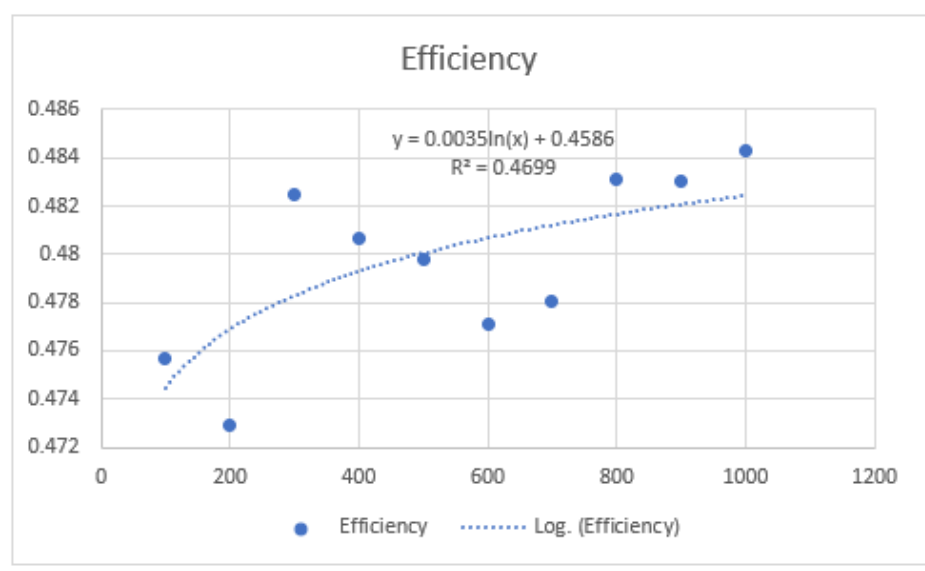

Figure 5 Efficiency chart by 200 population and generation number

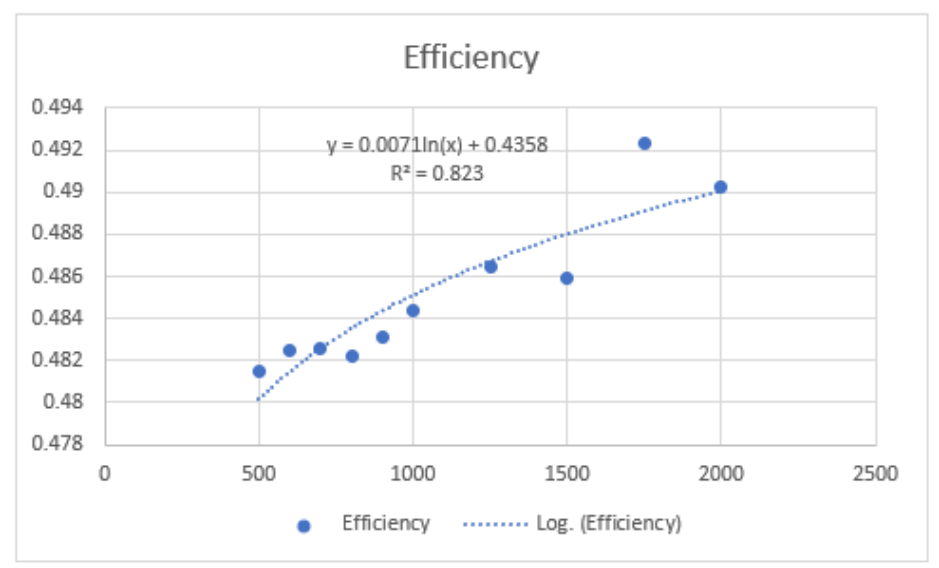

Figure 6 Efficiency chart by generation with 500 population

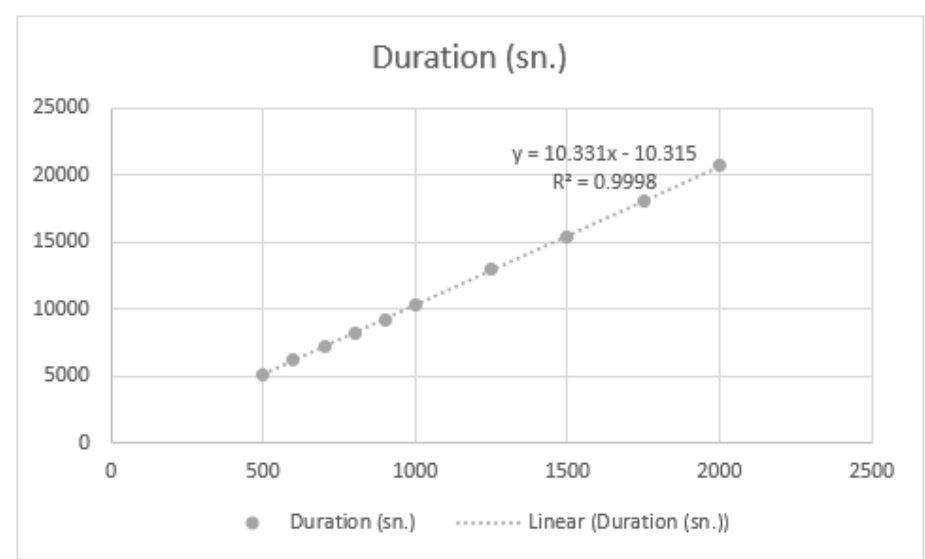



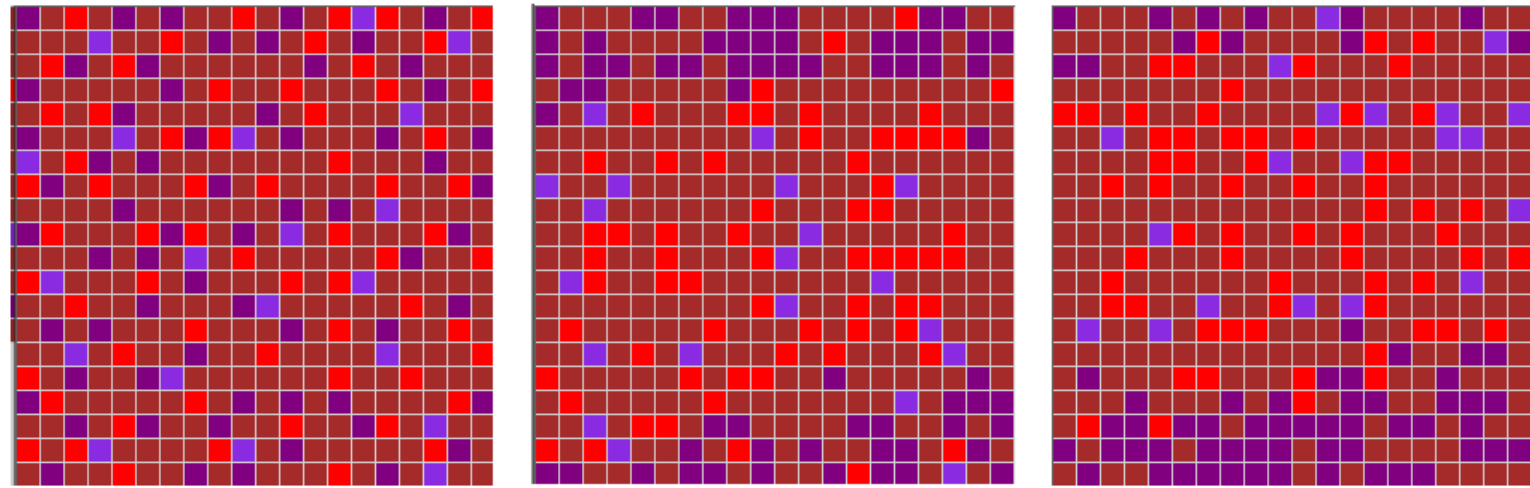

Figure 8 Layout patterns with 500 populations (Main layout, 500 generation, 2000 generation)

When the results of the analysis with 500 populations are examined, it seems that the industry tends to settle by clustering at the outermost part of the area, small clusters have formed between the trade and residentials, and the recreation areas are located in such a way that they are not very close to the industry and each other (Figure 8 ). These results are reached by running the application with 10 different generation numbers and the analysis lasted 31.5 hours.

According to these studies, it has been tried to create a statistical model that will provide a suitable population and number of generations according to the cell number. The software was run 100 times with different parameters and the results and parameters were analyzed.

The ratio of the efficiency value to the possible maximum efficiency value was determined as the dependent variable, and a multiple regression analysis was performed by multiplying the number of cells, population and generation. In this model, since the nature of the process is exponential, the $R^{2}$ value was found to be as low as 0.18 nevertheless the coefficients were found to be at the correct sign and appropriate. Also, it was observed that this correlation gave generally correct results in trials. (Figure 9).

SUMMARY OUTPUT

\begin{tabular}{lr}
\hline \multicolumn{2}{c}{ Regression Statistics } \\
\hline Multiple R & 0.417686088 \\
R Square & 0.174461668 \\
Adjusted R Square & 0.15744026 \\
Standard Error & 12.15110642 \\
Observations & 100 \\
\hline
\end{tabular}

\begin{tabular}{|c|c|c|c|c|c|}
\hline & $d f$ & SS & MS & $F$ & Significance $F$ \\
\hline Regression & 2 & 3026.677592 & 1513.338796 & 10.24954335 & 9.15707E-05 \\
\hline Residual & 97 & 14321.99057 & 147.6493873 & & \\
\hline Total & 99 & 17348.66816 & & & \\
\hline
\end{tabular}

\begin{tabular}{lrrrrrrrr}
\hline & Coefficients & Standard Error & \multicolumn{1}{c}{ t Stat } & \multicolumn{1}{c}{ P-value } & \multicolumn{1}{c}{ Lower 95\% } & \multicolumn{1}{l}{ Upper 95\% } & Lower 95.0\% & Upper 95.0\% \\
\hline Intercept & 81.22112752 & 1.395285437 & 58.21111963 & $2.96348 \mathrm{E}-77$ & 78.45187216 & 83.99038287 & 78.45187216 & 83.99038287 \\
Cell Count & -0.003325265 & 0.001151078 & -2.888827186 & 0.00476957 & -0.005609835 & -0.001040694 & -0.005609835 & -0.001040694 \\
PopGen & $4.51272 \mathrm{E}-06$ & $1.38535 \mathrm{E}-06$ & 3.257454674 & 0.001549806 & $1.76318 \mathrm{E}-06$ & $7.26226 \mathrm{E}-06$ & $1.76318 \mathrm{E}-06$ & $7.26226 \mathrm{E}-06$ \\
\hline
\end{tabular}

Figure 9 Multiple regression for efficiency success rate

$$
\text { ERatio }=81.22113+(\text { CellCount } *-0.0033252)+(P o p * G e n * 4.51272 E-06)
$$

ERatio $=$ Percentage of efficiency success (significant between 0 and 100)

CellCount $=$ Cell Number

Pop $=$ Population in a Generation 
Gen $=$ Generation Number

PopGen $=$ Population in a Generation times Generation Number

The process duration was determined as the dependent variable, the efficiency rate success percentage, cell number, population and generation number multiplication and the number of land use types were determined as independent variables, multiple regression analysis was performed. The $R^{2}$ value of this model was found to be as high as 0.78 and the coefficients were formed in the expected sign. (Figure 10)

\begin{tabular}{|c|c|c|c|c|c|}
\hline \multicolumn{2}{|c|}{ Regression Statistics } & & & & \\
\hline Multiple R & 0.885397033 & & & & \\
\hline R Square & 0.783927907 & & & & \\
\hline Adjusted R Square & 0.774830134 & & & & \\
\hline Standard Error & 3317.426167 & & & & \\
\hline Observations & 100 & & & & \\
\hline \multicolumn{6}{|l|}{ ANOVA } \\
\hline & $d f$ & SS & MS & $F$ & Significance $F$ \\
\hline Regression & 4 & 3793181142 & 948295285.5 & 86.16701723 & $9.46055 E-31$ \\
\hline Residual & 95 & 1045505055 & 11005316.37 & & \\
\hline Total & 99 & 4838686198 & & & \\
\hline
\end{tabular}

\begin{tabular}{lrrrrrrrr}
\hline & Coefficients & Standard Error & \multicolumn{1}{c}{ S Stat } & P-value & \multicolumn{1}{l}{ Lower 95\% } & Upper 95\% & Lower 95.0\% & Upper 95.0\% \\
\hline Intercept & -10900.83322 & 3382.775754 & -3.222452213 & 0.001741687 & -17616.49218 & -4185.174254 & -17616.49218 & -4185.174254 \\
Efficiency Ratio & 90.37696245 & 32.29970263 & 2.798074134 & 0.006224716 & 26.25394539 & 154.4999795 & 26.25394539 & 154.4999795 \\
Cell Count & 3.622790945 & 0.465145335 & 7.788513975 & $8.37824 \mathrm{E}-12$ & 2.699360702 & 4.546221189 & 2.699360702 & 4.546221189 \\
PopGen & 0.00435792 & 0.000398493 & 10.93601084 & $1.67962 \mathrm{E}-18$ & 0.003566812 & 0.005149028 & 0.003566812 & 0.005149028 \\
Land Use Type Count & 1307.332994 & 401.9883973 & 3.25216599 & 0.001585942 & 509.2851247 & 2105.380863 & 509.2851247 & 2105.380863 \\
\hline
\end{tabular}

Figure 10 Multiple regression results for process duration

$$
\begin{gathered}
\text { Dur }=-10900.83322+(\text { ERatio * } \\
\text { 90.37696 })+(\text { CellCount * 3.62279 })+(\text { Pop * Gen * 0.0043579 })+ \\
(\text { LandUSeCnt * 1307.33299 })
\end{gathered}
$$

Dur = Operation Time (seconds)

ERatio $=$ Percentage of Activity Success Rate (0-100)

CellCount $=$ Number of Cells

Pop $=$ Population in a Generation

Gen $=$ Number of Generations

PopGen = Population in a Generation times Generation Number

LandUseCnt $=$ Land Use Type Count

Using the above two equations, it has been examined how successful the application can yield in real cities. 6 cities of various sizes in Turkey are analyzed by dividing into cells of 300 meters width and height and how many cells will be used for analyses is determined. For analysis of 8 different land use types and $99 \%$ effectiveness success rate, how many population and generations are needed is determined and the duration of the processes was calculated with these parameters. According to the Table 3, it is estimated that a result with a successful efficiency value of $99 \%$ can be achieved with a processing time of about 1 day in small cities, the result can be achieved in 2 days in large cities, in a week in very large cities, and in 1.5 months in metropolitan-scale cities. 
Table 3 Application's estimated success performance analysis by cities

\begin{tabular}{|c|c|c|c|c|c|c|}
\hline & Very Small & Small & Medium & Large & Very Large & Metropolitan \\
\hline City Population & 55,300 & 125,000 & 306,000 & 900,000 & $3,000,000$ & $16,000,000$ \\
\hline Cell Count & 176 & 289 & 1,156 & 1,500 & 6,318 & 41,648 \\
\hline Land Use Type Count & 8 & 8 & 8 & 8 & 8 & 8 \\
\hline Population (Genetic Algorithm) & 500 & 650 & 800 & 1500 & 2500 & 4500 \\
\hline Generation & 8000 & 6500 & 6000 & 3500 & 3500 & 7700 \\
\hline Efficiency Success Ratio & 98.687 & 99.326 & 99.038 & 99.925 & 99.698 & 99.096 \\
\hline Execution Duration (second) & 33533.468 & 45135.970 & 129139.563 & 163436.542 & 631580.074 & 4065461.494 \\
\hline Execution Duration (hour) & 9.315 & 12.538 & 35.872 & 45.399 & 175.439 & 1129.295 \\
\hline Execution Duration (day) & 0.388 & 0.522 & 1.495 & 1.892 & 7.310 & 47.054 \\
\hline
\end{tabular}

A similar study with artificial data was also applied on Eskişehir in order to better understand this issue, and its real-world equivalent was examined.

Eskisehir is a city in Türkiye's Central Anatolia Region where population is 783.611 and $141 \mathrm{~km}^{2}$ urban area with well-developed industry and trade. Eskişehir's urban area is divided into 1000 meters wide and high (100 hectares) cells and existing land uses are assigned to these cells. 630 cells were created with 18 rows and 35 columns. Industry, trade-service, and residential areas have been determined as the land uses for which optimum layouts will be determined. 50 cell ( 5.000 h.a) housing, 7 cell ( 700 h.a) trade, 21 cell ( 2.100 h.a) industrial area have been determined in existing 2020 layout. (Figure 11) By examining the Eskişehir Master Plan for 2030, it was determined that the distribution of these land uses was planned as 70 cell resident ( 7.000 h.a), 15 cells ( 1.500 h.a) trade, 47 cells ( 4.700 h.a) industrial area. (Eskişehir Municipality, 2015) Using the application, the best distribution of 20 residences, 8 commercial and 26 industrial cells was tried to be determined. In this scenario, it is accepted that the existing residential areas can be transformed into trade and industry, but the functions of the existing commercial and industrial areas will not change. The transportation and land value parameters in Table 1 and Table 2 were used, and the effect alpha parameter of transportation was taken as 2 . The application was run using the values in Table 4.

Table 4 Optimum plan parameters used for Eskisehir

\begin{tabular}{|c|c|}
\hline & Value \\
\hline Max Value For Transport & $1,500,000.0$ \\
\hline Max Value For Land Value & $12,000.0$ \\
\hline Importance Ratio For Transport & 0.25 \\
\hline Importance Ratio For Land Value & 0.75 \\
\hline
\end{tabular}

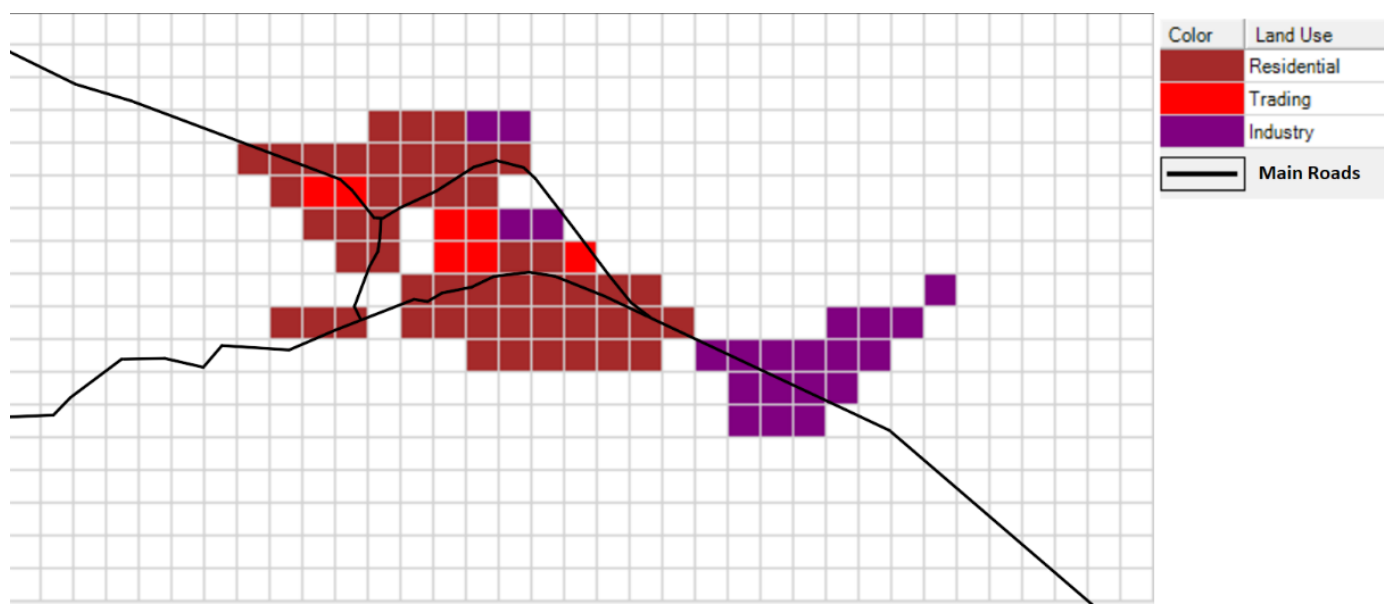

Figure 11 Eskişehir 2020 existing land use 
The land use types to be added for the first layout of the application were randomly placed and population and generation numbers were found using the above efficiency and duration equations. The application was run with the parameters in Table 5 and the results in this table were obtained. The alternatives formed as a result of the analysis are shown in Figure 12, Figure 13, Figure 14, Figure 15. The analysis with 5700 generations reached the highest efficiency value. Later, the result of 5700 generations was accepted as the initial layout and analyzes were made. In these analyzes, the best layout after each analysis was used as initial layout and this layout was tried to be improved. The results of these studies are shown in Table 3. Result of these studies, the layout with the best efficiency value of 0.50411 was reached after approximately 15 hours of calculation. This layout is shown in Figure 16.

Table 5 Analysis parameters and results made with different generation numbers

\begin{tabular}{|c|c|c|c|c|c|}
\hline & Population & Generation & Mutation Rate(\%) & Duration (hh:mm) & Efficiency \\
\hline 1. Try & 800 & 800 & 20 & $00: 55$ & 0.46836 \\
\hline 2. Try & 800 & 1250 & 20 & $01: 23$ & 0.46316 \\
\hline 3. Try & 800 & 2500 & 20 & $02: 46$ & 0.46942 \\
\hline 4.Try & 800 & 5700 & 20 & $06: 07$ & 0.46430 \\
\hline
\end{tabular}

Table 6 Parameters and results of analyzes made to optimize the 5700-generation layout

\begin{tabular}{|c|c|c|c|c|c|}
\hline & Population & Generation & Mutation Rate(\%) & Duration (hh:mm) & Efficiency \\
\hline 5. Try & 500 & 2500 & 20 & $01: 45$ & 0.47978 \\
\hline 6. Try & 500 & 2500 & 20 & $01: 44$ & 0.49097 \\
\hline 7. Try & 800 & 4000 & 20 & $04: 18$ & 0.49965 \\
\hline 8.Try & 500 & 2000 & 20 & $01: 22$ & 0.50411 \\
\hline
\end{tabular}

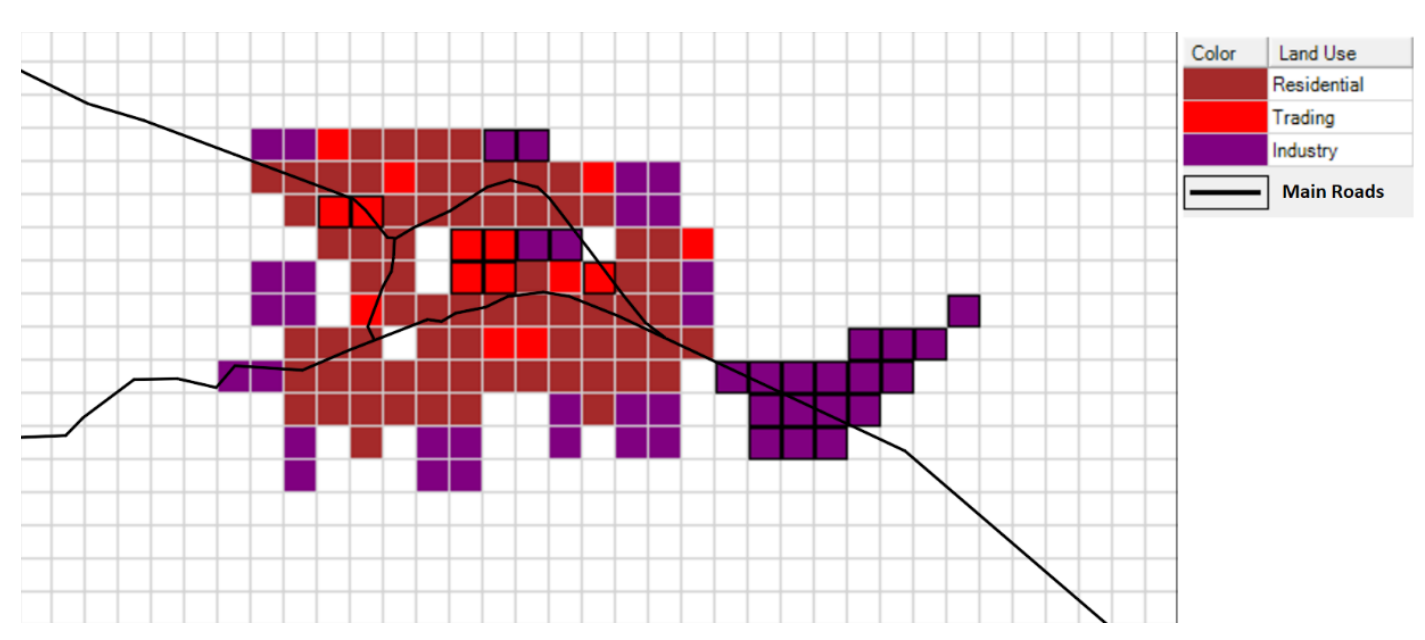

Figure 12800 Population, 800 generation layout 


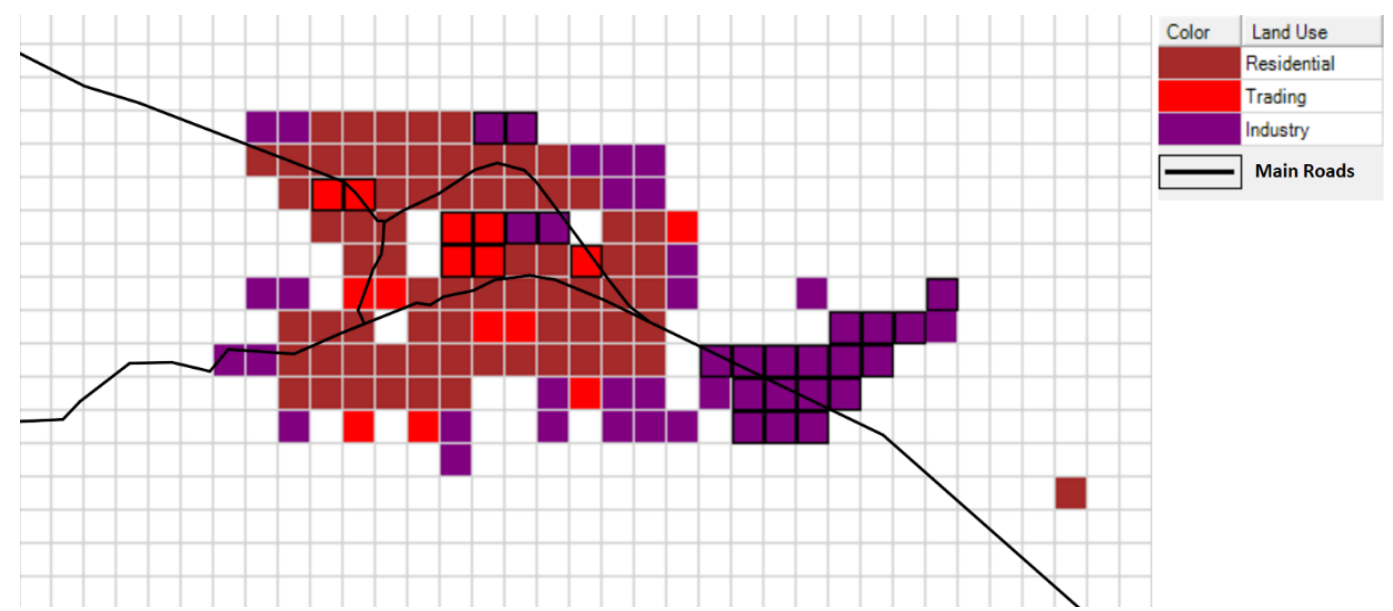

Page | 28

Figure 13800 Population, 1200 generation layout

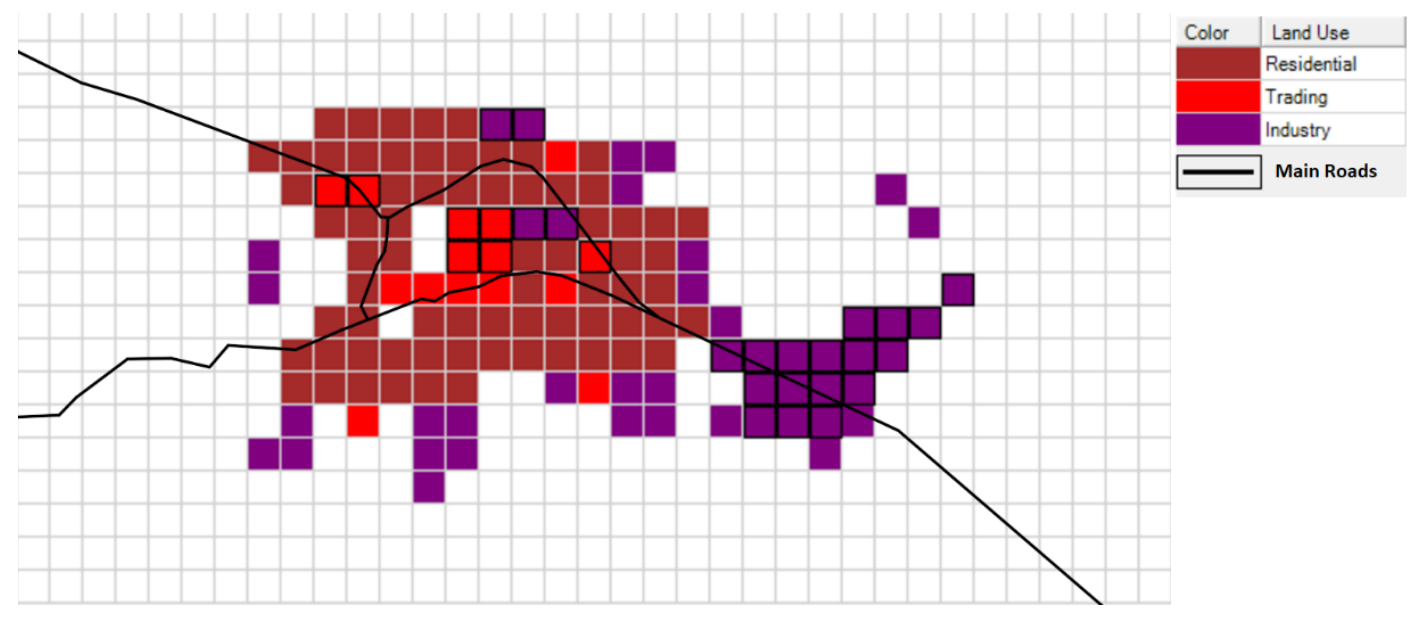

Figure 14800 Population, 2500 generation layout

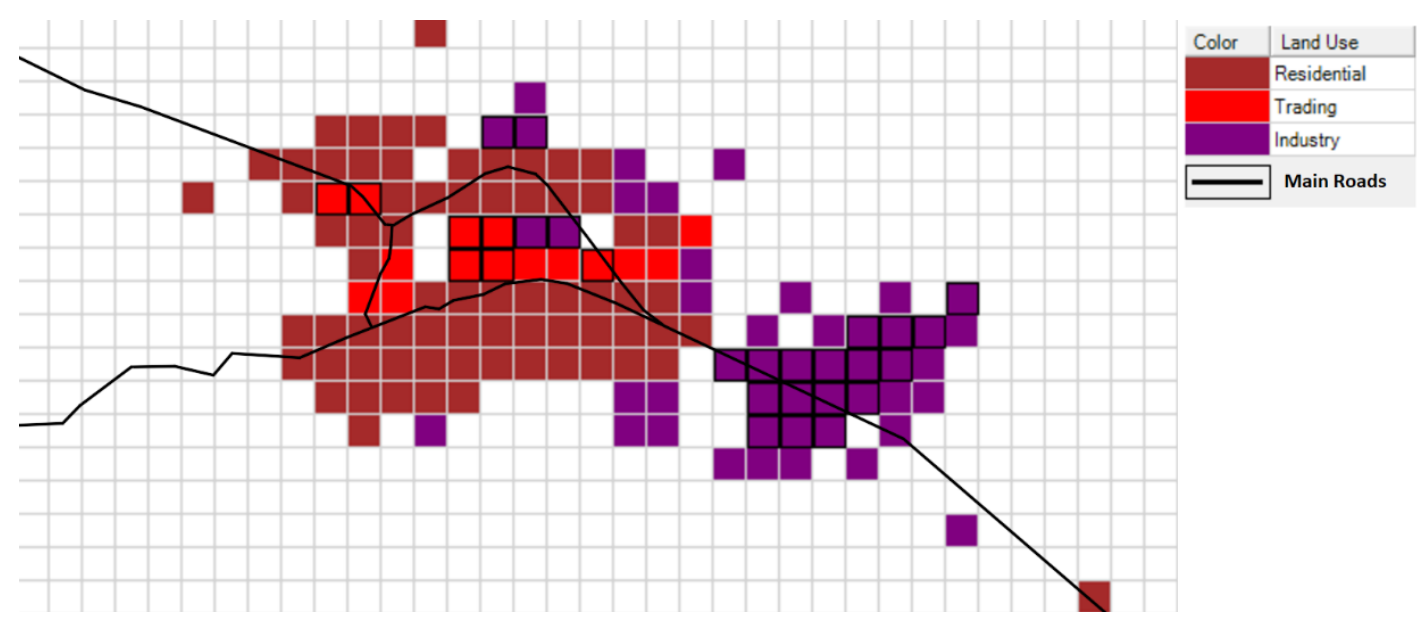

Figure 15800 Population, 5700 generation layout 


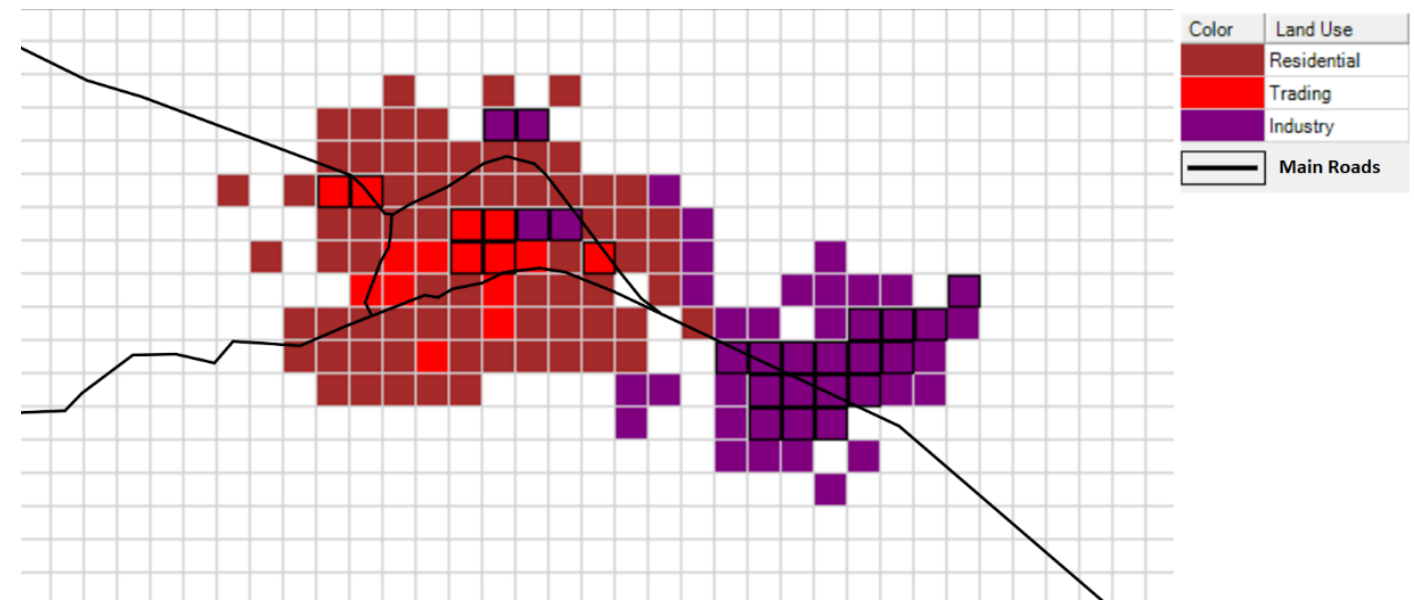

Figure 16 The layout with the highest efficiency value

When the results and layouts produced by the application are examined, it is thought that this method and application will be useful in order to produce more efficient layout alternatives in acceptable time.

\section{Conclusion}

As a result of this study, it has been shown that the problem of finding the best layout plan according to the transportation and land value effect can be solved in a reasonable time with the genetic algorithm, even if the best layout cannot be found, with the best layouts produced and analyzed with different parameters, the features of the most effective layout can be determined. Klosterman (2008) accepts 4 design principles regarding planning tools. All models are wrong, some models are useful, it is difficult to predict the future, the models should be simple, the present model is the best available data. It is thought that the method developed according to these principles can be useful to experts with its simple use, less data requirement and reasonable performance.

Tong \& Murray (2012) stated that spatial optimization studies will focus on the issues of abstraction and representation of data, evaluation of multiple goals and constraints and Geographic Information System integration in the future. Planners develop their designs by producing different alternatives and comparing them. With the additions to the developed genetic algorithm, instead of focusing on a single alternative, an algorithm can be prepared that produces different alternative results in a specified number. Feng \& Lin (1999) and Cao et al. (2011) addressed this problem and tried to produce and evaluate different alternatives for their objectives. In addition, this method does not take into account the facility-location hierarchy observed in multi-center cities. More realistic layout plans can be produced by developing model constraints to simulate hierarchy in the city. By increasing the objective functions, it can be ensured that it includes features such as environment, economy and livability. Some more appropriate methods can be used to evaluate multi-objective functions and constraints together more accurately. As an example of these methods, Masoomi et al. (2013) use the Analytical Hierarchy Process method and structured binary comparison methods to optimize multiple objectives.

As Schwaab et al. (2018) stated by, developing problem-specific heuristic algorithms is critical for developing applications that reach the optimum solution in a shorter time. In order to develop such algorithms, it would be useful to examine the use of experts' domain knowledge. Performance increases may be experienced with the improvements in the calculation process to be made in parallel with the developments in software and hardware. Ensuring that the calculation of the efficiency value can be done on the Graphics Processing Unit (GPU) will shorten the operation time of the process and make it a more useful tool. Zhou \& Tan (2009) developed an application of the 
Particle Swarm Optimization algorithm using GPU and stated that this application can run 10 times faster than the version using CPU. It is thought that such a performance increase will greatly increase the possibility of using such methods in real problems.

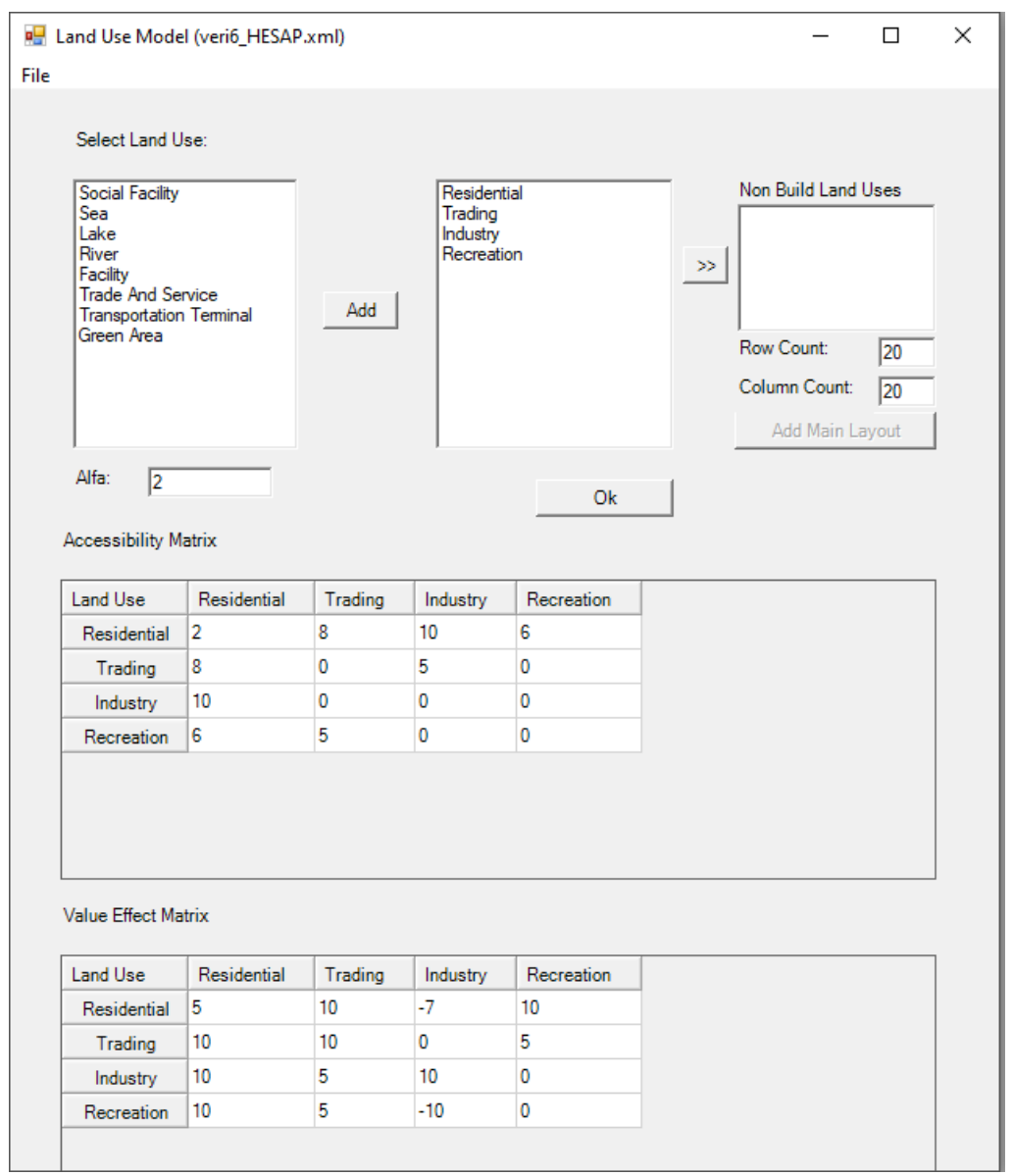

Figure 17 Inputs of the application

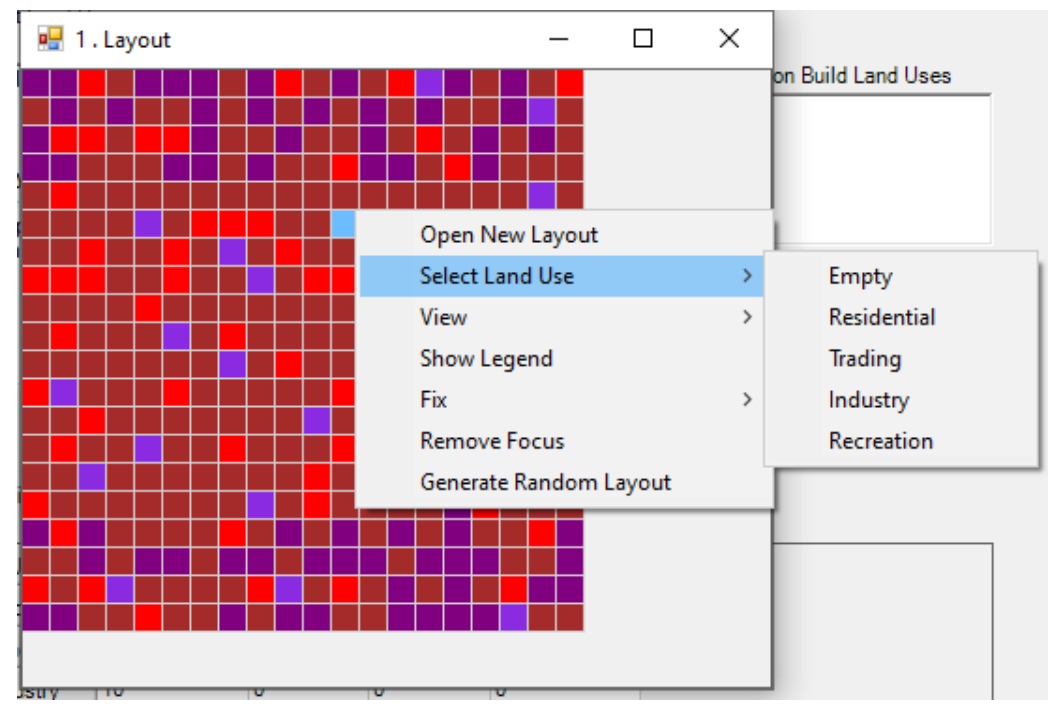

Figure 18 Layout preparation operations 
喝 Land Use Numbers

Operations

Land Use Numbers:

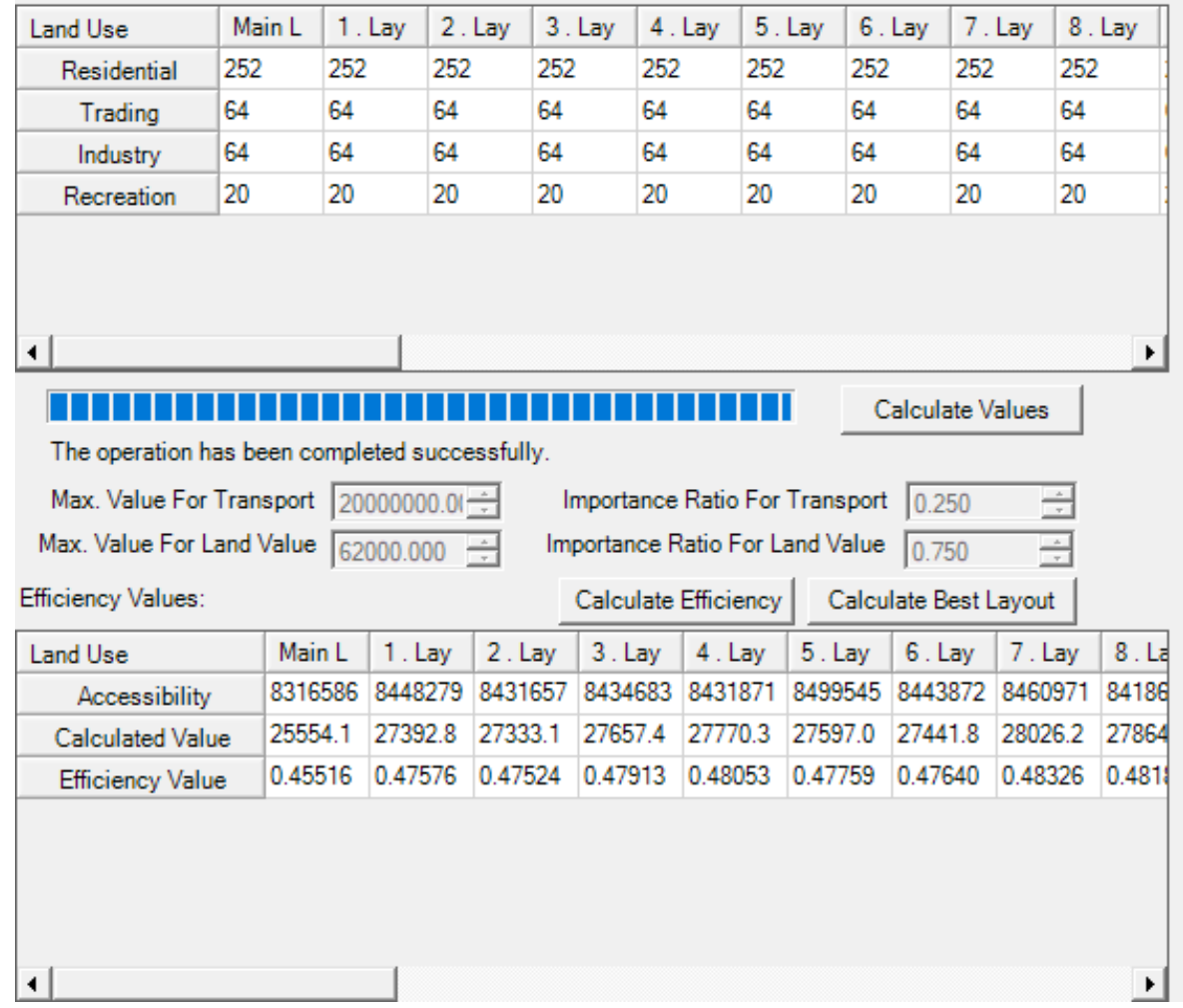

晿 Best Layout Parameters $\quad-\quad \square \quad \times$

\begin{tabular}{llll|}
\cline { 2 - 3 } Population Size & 1300 & $\vdots$ \\
Generation Count & 200 & $\vdots$ \\
Mutation Ratio (\%) & 10.00 & $\vdots$ \\
How Many Cell Later Effect Be 0 & 0 & & $\vdots$ \\
& & & Ok \\
\end{tabular}

Figure 19 Results and best layout parameters

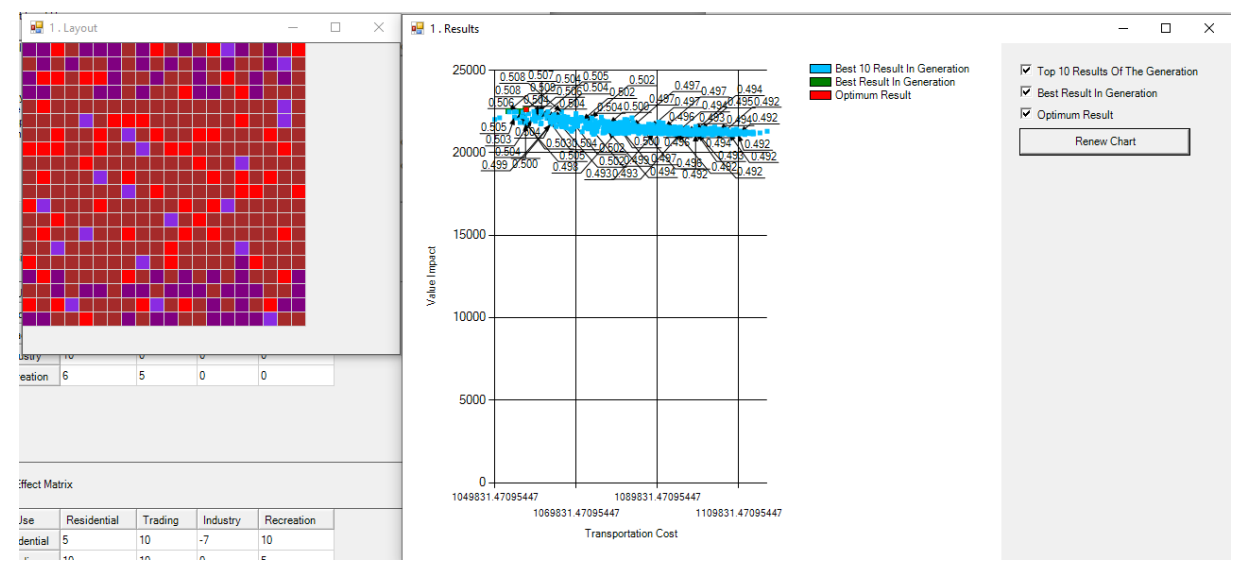

Figure $\mathbf{2 0}$ Best results graph of result layout and generations 


\section{References}

Arslanlı, Y. K. (2016). Hansen Re-Visited: Alternative Methodology for Istanbul Landuse Pattern. Iconarp International J. of Architecture and Planning, 4(2), 58-80. https://doi.org/10.15320/iconarp.2016.7

Cao, K., Batty, M., Huang, B., Liu, Y., Yu, L., \& Chen, J. (2011). Spatial multi-objective land use optimization: extensions to the non dominated sorting genetic algorithm II. International Journal of Geographical In formation Science, 25(12), 1949-1969. https://doi.org/10.1080/13658816.2011.570269

Dökmeci, V. (2015). Planlamada Sayısal Yöntemler (2nd ed.). İstanbul: iTü Vakfı Yayınları.

Eldrandaly, K. (2010). A GEP-based spatial decision support system for multisite land use allocation. Applied Soft Computing, 10(3), 694-702 Retrieved.from https://linkinghub.elsevier.com/retrieve/pii/S1568494609001379

Eskişehir Municipality. (2015). Eskişehir Metropolitan Area Master Plan Report. Retrieved from http://www.eskisehir.bel.tr/dosyalar/imar_plan_ilani/211-5-2016-09-28-87d89f43.pdf

Feng, C.-M., \& Lin, J.-J. (1999). Using a genetic algorithm to generate alternative sketch maps for urban planning. Computers, Environment and Urban Systems, 23(2), 91-108. https://doi.org/10.1016/S01989715(99)00004-6

Haque, A., \& Asami, Y. (2014). Optimizing urban land use allocation for planners and real estate developers. Computers, Environment and Urban Systems, 46, 57 69.https://doi.org/10.1016/j.compenvurbsys.201 4.04.004

Klosterman, R. E. (2008). A new tool for a new planning: The What IfTM planning support system. Planning Support Systems for Cities and Regions, 1(1), 85-99.

Li, X., \& Parrott, L. (2016). An improved Genetic Algorithm for spatial optimization of multi-objective and multi-site land use allocation. Computers, Environment and Urban Systems, 59, 184-194. https://doi.org/10.1016/J.COMPENVURBSYS.2016.07.002

Liu, Y. Y., Tang, W., He, J., Liu, Y. Y., Ai, T., \& Liu, D. (2015). A land-use spatial optimization model based on genetic optimization and game theory. Computers, Environment and Urban Systems, 49, 1-14. https://doi.org/10.1016/J.COMPENVURBSYS.2014.09.002

Loonen, W., Heuberger, P., \& Kuijpers-Linde, M. (2007). Spatial optimization in land-use allocation problems. In Modelling land-use change (pp. 147-165). Springer, Dordrecht.

Masoomi, Z., Mesgari, M. S., \& Hamrah, M. (2013). Allocation of urban land uses by Multi-Objective Particle Swarm Optimization algorithm. International Journal of Geographical Information Science, 27(3), 542566. https://doi.org/10.1080/13658816.2012.698016

Rogers, E. M. (2003). Diffusion of Innovations (5th ed.). The Free Press.

Schwaab, J., Deb, K., Goodman, E., Lautenbach, S., van Strien, M. J., \& Grêt-Regamey, A. (2018). Improving the performance of genetic algorithms for land-use allocation problems. International Journal of Geographical Information Science, 32(5), 907-930. https://doi.org/10.1080/13658816.2017.1419249

Stewart, T. J., Janssen, R., \& van Herwijnen, M. (2004). A genetic algorithm approach to multiobjective land use planning. Computers \& Operations Research, 31(14), 2293-2313. https://doi.org/10.1016/S03050548(03)00188-6

Taşkın, Ç., \& Emel, G. G. (2009). Sayısal Yöntemlerde Genetik Algoritmalar (1st ed.). Alfa Aktüel.

Tong, D., \& Murray, A. T. (2012). Spatial Optimization in Geography. Annals of the Association of American Geographers, 102(6), 1290-1309. https://doi.org/10.1080/00045608.2012.685044

Xia, Y., Liu, D., Liu, Y., He, J., \& Hong, X. (2014). Alternative zoning scenarios for regional sustainable land use controls in China: A knowledge-based multiobjective optimisation model. International Journal of Environmental Research and Public Health, 11(9), 8839 8866. https://doi.org/10.3390/ijerph1109088 39

Zhou, Y., \& Tan, Y. (2009). GPU-based Parallel Particle Swarm Optimization. 2009 IEEE Congress on Evolutionary Computation, (2), 1493-1500. https://doi.org/10.1109/CEC.2009.4983119

\section{Resume}

Hasan Mutlu has been working as a software specialist for 14 years for Netcad which has been developing GIS and CAD applications. He develops CAD and GIS based software related to civil engineering and city planning. He specializes in developing optimization algorithms on these fields. He took part in various Planning and Research Projects (Istanbul Metropolitan Area Plan (2005) - istanbul Historical Peninsula Plan (2001)) as a consultant. He has academic articles in international/national journals and several conference papers in international conferences. 